$\begin{array}{ll} & \text { Etnográfica } \\ \text { etnográfica } & \text { Revista do Centro em Rede de Investigação em }\end{array}$

Antropologia

vol. $26(1) \mid 2022$

Vol. 26 (1)

\title{
(In)justicia e (i)legalidad bajo la ciudad: las relaciones entre policías y vendedores en el metro de la Ciudad de México
}

In)justiça e (i)legalidade na cidade. Relações entre polícia e vendedores no metrô da Cidade do México

\section{Erick Serna Luna}

\section{OpenEdition}

Journals

\section{Edición electrónica}

URL: https://journals.openedition.org/etnografica/11231

DOI: 10.4000/etnografica.11231

ISSN: 2182-2891

\section{Editor}

Centro em Rede de Investigação em Antropologia

Edición impresa

Paginación: 89-107

ISSN: 0873-6561

\section{Referencia electrónica}

Erick Serna Luna, «(In)justicia e (i)legalidad bajo la ciudad: las relaciones entre policías y vendedores en el metro de la Ciudad de México», Etnográfica [En línea], vol. 26 (1) | 2022, Publicado el 25 febrero 2022, consultado el 30 junio 2022. URL: http://journals.openedition.org/etnografica/11231 ; DOI: https://doi.org/10.4000/etnografica.11231

\section{(c) (7) (8)}

Etnográfica is licensed under a Creative Commons Attribution-NonCommercial 4.0 International License. 


\section{(In)justicia e (i)legalidad bajo la ciudad. Las relaciones entre policías $\mathrm{y}$ vendedores en el metro de la Ciudad de México}

Erick Serna Luna

El artículo muestra como las relaciones entre comerciantes populares y policías del metro de la Ciudad de México se desarrollan dentro de una política de estigmatización y criminalización del comercio popular. Una política que, sostengo, descansa en una concepción teórica que rechaza al comercio popular como una actividad productiva y como un trabajo digno. Así, entre las prohibiciones y la estigmatización, las relaciones entre comerciantes populares, policías y jueces cívicos, se caracterizan por la corrupción y la violencia. El primer aspecto, permite la negociación de la aplicación de la ley y funda la base de una economía sustentada por las ilegalidades del Estado. Por su parte, la violencia se expresa en la brutalidad policiaca en contra de las personas que realizan el comercio popular en el metro, la cual, ya ha tenido consecuencias fatales.

PALABRAS CLAVE: metro, comercio popular, etnografía, ilegalidad, actuar policiaco.

In)justiça e (i)legalidade na cidade. Relações entre polícia e vendedores no metrô da Cidade do México - O artigo mostra como as relações entre os comerciantes populares e a polícia metropolitana da Cidade do México se desenvolvem dentro de uma política de estigmatização e criminalização do comércio popular. Uma política que, defendo, se apoia numa conceção teórica que rejeita o comércio popular como atividade produtiva e como trabalho decente. Assim, entre proibições e estigmatizações, as relações entre comerciantes populares, polícias e juízes cíveis são caracterizadas pela corrupção e pela violência. O primeiro aspeto permite a negociação da aplicação da lei e estabelece as bases de uma economia sustentada pelas ilegalidades do Estado. Por sua vez, a violência expressa-se na brutalidade policial contra os praticantes do comércio popular do metro, que já teve consequências fatais.

PALAVRAS-CHAVE: metro, comércio popular, etnografia, ilegalidade, fraude policial.

SERNA LUNA, Erick (eserna@colmex.mx) - Investigador asociado del Seminario sobre Trabajo y Desigualdad (TraDes), El Colegio de México. 
INVESTIGAR LA (IN)JUSTICIA Y LA (I)LEGALIDAD EN TIEMPOS DE PANDEMIA

La pandemia por Covid-19 que se desató en todo el mundo desde finales del 2019 tuvo un impacto devastador en todas las esferas de la vida. En el caso de las personas comerciantes populares del metro de la Ciudad de México, la pandemia se conjuntó con un incremento en la criminalización de sus actividades por parte de las autoridades y por los grupos de policías que resguardan las estaciones del metro de la Ciudad de México. Justo cuando la violencia policiaca en contra de los comerciantes populares cobró la vida de un vendedor (Serna Luna 2020b), el gobierno de la Ciudad de México decretó la Jornada de Sana Distancia el 23 de marzo de 2020. Así, los comerciantes vagoneros tuvieron que enfrentar dos vulnerabilidades: el riesgo de contagiarse de Covid-19 y el padecimiento de la violencia policiaca (Serna Luna 2020b).

Debido al distanciamiento y el confinamiento que se instauró con la finalidad de reducir los contagios por Covid-19, tuve que distanciarme del grupo de vagoneros. Aunque mantuve contacto con ellos por Whatsapp, no los había vuelto a ver. Hasta el 26 de febrero de 202 l, en el que me reuní con La Rana y Dupa en un restaurante al sur de la Ciudad de México. La Rana es el representante de una de las organizaciones de comerciantes vagoneros y vagoneras que ha cobrado mayor fuerza política en los últimos años. Mientras que Dupa es un artista vagonero de abolengo, con más de 30 años declamando, cantando y actuando en los vagones de varias líneas del metro.

Esa tarde, La Rana habló sobre las estrategias políticas para contrarrestar las campañas de criminalización en contra de las personas vagoneras. Mientras que Dupa comentaba parte de su historia de vida en los vagones del metro. Fue casi al finalizar nuestra charla que Dupa, con entusiasmo, nos contó:

"Saben, he estado pensando en unos versos, en realidad es como un rap en el que denuncio todos los abusos que vivimos como vagoneros, se llama 'Soy vagonero' y va más o menos así:

Yo soy vagonero hasta los huesos,

perseguido por sabuesos,

y por ganarme unos pesos,

soy uno más de los presos.

En el metro me gano la vida

vendiendo chicles y alegrias

trabajando todo el día,

si es que no me agarra el policía

Que abusando de su autoridad,

quiere quitarme la mercancía, además de arrestarme 
y llevarme con un juez de porquería.

Yo le vendo al pasajero

y me escondo como puedo,

para que no me agarre el puerco ${ }^{1}$

y me quite el dinero,

producto del esfuerzo

con el que mantengo a los que quiero

¡¿Entiendes, pinche puerco?!

Por la familia en la línea yo me muero."

[charla con La Rana y Dupa, 26 de febrero de 2021]

El rap de Dupa muestra del ingenio que caracteriza al comercio popular en el metro, permite apreciar las tensas relaciones que existen entre los policiacos y las personas comerciantes populares. Las cuales permiten identificar las relaciones entre lo legal y lo ilegal que caracterizan a la tensión entre comerciantes y grupos policiacos, así como la aplicación de la ley hacia grupos moral y jurídicamente criminalizados, como es el caso de las personas comerciantes.

El artículo inicia discutiendo las distinciones entre lo popular y lo criminal, enfatizando sobre la heterogeneidad del comercio popular en el metro. En segunda instancia, se habla sobre el metro de la Ciudad de México, describiendo su composición administrativa y jurídica. Posteriormente, se analiza la aplicación de las normas jurídicas en contra de los comerciantes populares, las cuales son el ejemplo de la política de criminalización en contra del comercio popular en el metro. Por último, se ofrecen algunas reflexiones sobre el presente y el futuro de las relaciones entre autoridades y personas comerciantes en este medio de transporte.

\section{ENTRE LO POPULAR Y LO CRIMINAL: DISTINCIONES SOCIO-MORALES}

Un aspecto para destacar en torno a la criminalización del comercio popular es la revisión de las categorías socio-morales con las que se nombran a los comerciantes populares, pues sostengo que detrás de los conceptos que se emplean, existe un trasfondo moral estigmatizante que, en gran medida, se vincula con la criminalización del comercio popular. Para ello, en el seno de la teoría de las clases sociales de Marx, haré un breve análisis sobre las concepciones del lumpenproletariado y la noción de la informalidad que Keith Hart derivó del análisis marxista del lumpenproletariado para nombrar a las personas que comerciaban y realizaban otras actividades económicas en la ciudad de Accra. 
Desde los tiempos del desarrollo industrial en Inglaterra se gestó una diferenciación dentro del mundo del trabajo entre aquellas personas que laboraban en las nacientes industrias y quienes obtenían sus ingresos por medio de otras actividades (Denning 2010: 79-80). Una división que segmentaría el mundo del trabajo entre trabajadores asalariados, quienes vendían su fuerza de trabajo en las industrias y, posteriormente, en las empresas; y aquellas personas no asalariadas, quienes ejercían su fuerza de trabajo en actividades o servicios por cuenta propia (Pacheco 2004).

Una división laboral que dentro del esquema del materialismo histórico de Karl Marx cobraría tintes políticos y morales, al hablar del trabajador proletariado y el lumpenproletariado. Entendiendo por el primero aquél que vendía su fuerza de trabajo dentro de una relación capitalista con el dueño de los medios de producción; un trabajador con consciencia de clase quien, eventualmente, lucharía por una distribución más justa del plusvalor que obtenía el empresario al explotar su fuerza de trabajo (Marx 1999). Por el otro lado, el lumpenproletariado, el segmento desclasado de la fuerza de trabajo que integraba los ejércitos de reserva, la fuerza de trabajo que había sido absorbida del todo por el capital; estrato en el que Marx (1962: 120; 1999: 545-546) también agrupaba al ladrón, al mendigo y la prostituta, el germen del que se valían las clases dominantes para suprimir la lucha del proletariado (Marx 2003: 63-64).

La distinción que hacía Marx entre el proletariado y el lumpenproletariado no sólo estaba fundada en la relación que tenían las personas respecto de los medios de producción, sino que el análisis de las relaciones de producción de Marx estaba vinculado con su análisis y compromisos políticos. De tal modo, en el lumpenproletariado podemos encontrar que es una clase que no sólo fue construida con relación a los medios de producción, sino que también en esa clasificación se encuentran vestigios de la moralidad de su tiempo y de su sociedad.

Michael Denning (2010) ha identificado que el ingreso y el trabajo no deberían ser factores que determinaran el acceso a derechos humanos ni la conformación de las clases trabajadoras. No obstante, las antiguas distinciones entre las clases (Bourdieu 1988) que se construyen con base en la concepción moral de lo que se considera como trabajo y, en contraste, lo que se considera como actividades no laborales, tales como el comercio, el arte urbano, la mendicidad y otros oficios. Actividades que, desde esta perspectiva moral del trabajo, se ponen al mismo nivel de las actividades delictivas.

Keith Hart (1973), quien bebe del manantial de Marx (Schouten 2013: 2), elaboró el concepto de economía informal como una forma de entender las actividades económicas del "subproletariado" africano. ${ }^{2}$ Sin proponérselo, este 
estudio sería el principio de una tradición de pensamiento avocada al estudio de las actividades económicas y las poblaciones que las realizan. Actividades que, siguiendo el planteamiento de Marx, no se realizan al interior de las fábricas y empresas ni se rigen bajo el esquema de la relación de producción entre trabajo y capital, ${ }^{3}$ sino que son actividades que se desarrollan en las calles y espacios públicos de las ciudades. De allí que Hart, ahora apoyándose en Weber, entienda como informales las actividades comerciales que no siguen con la lógica y la racionalidad de las actividades económicas realizadas por las industrias y empresas (Schouten 2013).

Tanto Marx como Hart parten de una concepción moral de las actividades económicas del lumpenproletariado o del subproletariado. En primera instancia, para Marx, las poblaciones del lumpenproletariado no interesan para la economía política. Incluso porque considera que su fuerza laboral no es útil desde una relación de producción, no tiene valor para el capital, además de que son poblaciones desdeñables por ser políticamente adversas a las luchas del proletariado (Marx 2003: 63-64). ${ }^{4}$ En tanto para Hart las actividades comerciales de los frafras en las calles de Accra son "informales", porque no se ciñen a la racionalidad moderna del trabajo en la industria y las empresas.

Si bien el contexto histórico social que observaron Marx y Hart les permitía entender a estas actividades y las poblaciones que las realizan como "un sector no integrado a la productividad", hoy en día, con cifras como las de México, que ha tenido por varios años más del $50 \%$ del PIB producido por las llamadas actividades informales (Pacheco 2004), es complicado hablar de que estas poblaciones subproletariadas estén separadas del proceso productivo. ${ }^{5}$ Por otro lado, considero que entender al lumpenproletariado como una población "no productiva" y no apegada a las formas "racionales", tal como lo señalan Marx y Hart, derivó en un juicio valorativo a través del cual se excluyó moralmente a esta población del proceso productivo de la sociedad (Denning 2010). Con base en los propios fundamentos del esquema de clases de Marx, recalco el

de investigación: “iEl 'ejército de reserva de los desempleados y subempleados urbanos' realmente constituye un pasivo, mayoritariamente explotado en ciudades como Accra, o sus actividades económicas informales poseen alguna capacidad autónoma para generar crecientes incrementos para los pobres urbanos (rurales)?" (Hart 1973: 61).

3 Un resumen reciente y actualizado sobre este debate se puede encontrar en Crossa (2018).

4 En el contexto de las luchas de la Comuna de París, Marx vincula al lumpenproletariado con el apoyo al régimen de Luis Bonaparte. Así, afirma Marx que “[...] formó Bonaparte la solera de la sociedad del 10 de diciembre, 'sociedad de beneficencia' en cuanto que todos sus componentes sentían, al igual que Bonaparte, la necesidad de beneficiarse a costa de la nación trabajadora. Este Bonaparte, que se erige en jefe del lumpemproletariado, que sólo en éste encuentra reproducidos en masa los intereses, que él personalmente persigue, que reconoce en esta hez, desecho y escoria de todas las clases, la única clase en la que puede apoyarse sin reservas, es el auténtico Bonaparte" (Marx 2003: 64).

5 Una crítica que ya se hacía a las posturas de la informalidad desde inicios de los años 90 (Castells y Portes 1995). 
peso político, económico y social que tienen las poblaciones del lumpenproletariado. Para ello, me apoyo en la noción socio-histórica de clases populares definida por Clara Lida (1997: 4), como aquellas que: “[...] abarcaban a quienes participaban en el mundo del trabajo en el campo y en la ciudad: pequeños labradores, o jornaleros; artesanos, obreros en talleres y fábricas, del pueblo ocupado en servir; actividades del pequeño comercio o el taller, los tenderos, los empleados, los maestros de oficio". ${ }^{6}$

Las actividades económicas de las clases populares, como las describe Lidia, con la salvedad de los obreros, se desarrollan en espacios que no son ni industrias, ni empresas, sino que, tal y como observó Hart con los habitantes de Accra, son actividades que se desarrollan en el espacio público. Esta relación entre actividades populares y espacio público ha sido mejor desarrollada por Mario Barbosa Cruz (2008: 87), quien identificó el trabajo que se realizaba en las calles de la Ciudad de México a inicios del siglo Xx, como la venta de alimentos que realizaban generalmente las mujeres indígenas y las personas vinculadas a las actividades del campo que tendían sus petates en las calles; las personas que vendían alimentos preparados; los vendedores de productos en abonos, un sistema de crédito popular, en su mayoría, personas inmigrantes de España, Grecia e Italia; por último, las personas que ofrecían servicios en el espacio público, afiladores, zapateros, fotógrafos, escribanos, cantantes, actores, notarios y otras personas que realizaban sus oficios en las calles.

La segunda parte del extenso rap de Dupa describe una parte de las características sociolaborales que distinguen al comercio popular de las personas vagoneras del metro:

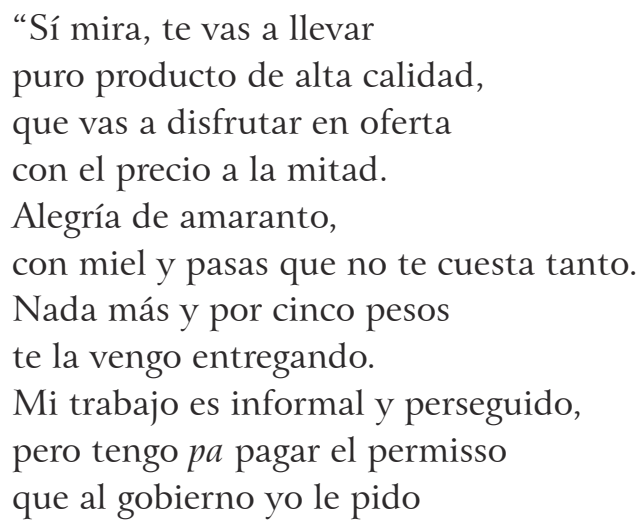

6 Una reflexión similar a la que realizó Hobsbawn (2001: 153) al hablar de la "turba": "¿Qué era la turba? Su fuerza principal residía en las capas generalmente descritas en el continente europeo como 'bajo pueblo' [...] señaladamente el de ciertos barrios antiguos, con unidad propia de las urbes [...] venía a ser una combinación de asalariados, pequeños propietarios y los inclasificables desheredados urbanos". 
y no me quiere dar.

Caminando por el tren entre vagones,

yo voy gritando mis pregones,

con los dulces que me compres,

sacaré pa los frijoles.

Pasajero, traigo buena oferta

escondida en la maleta,

con dulces, chicles y paletas

pa que nadie se la pierda.

Son para dama o caballero,

los productos que te ofrezco,

a los mejores precios,

pa que veas que te aprecio.

Para el hogar, taller y oficina

pura merca de la fina

de moda y novedad

a ti te va a encantar

la pura variedad

que te vengo a entregar"

[charla con La Rana y Dupa, 26 de febrero de 2021].

Las coplas de Dupa permiten apreciar la dinámica que caracteriza la vida del comercio popular en el metro, una heterogeneidad de pregones y mercancías, que en otras latitudes ha sido apreciada como un valor sociocultural (Pires 2011), y que también remite las diferentes poblaciones que ejercen sus actividades económicas en los pasillos y vagones del metro. Sólo que, como mostraré en esta sección, dicha heterogeneidad no sólo se expresa en términos socioeconómicos, sino que también se traduce en distinciones socio-morales.

Estas distinciones son presentadas en el siguiente mapa socio-moral sobre las distintas poblaciones que realizan sus actividades económicas en el mercado popular del metro. En el gráfico distingo entre las distintas poblaciones según sus conexiones morales y económicas en relación con el proceso de distribución de las mercancías, y en función con el espacio del STC Metro, entendido como un espacio social y no sólo como un transporte público. Las actividades populares que se desarrollan en metro incluyen al comercio popular, las formas de la mendicidad y el arte urbano del subterráneo; pero, también, identifica y distingue otras actividades ilícitas, como el robo de carteras y celulares, realizado por los llamados "panchitos" o carteristas.

La heterogeneidad poblacional también se ve reflejada en las relaciones jurídicas y administrativas que las autoridades mantienen con las poblaciones que integran el mercado popular en el metro. Por ejemplo, en relación con las personas con discapacidad visual que comercian y mendigan en el metro, por 


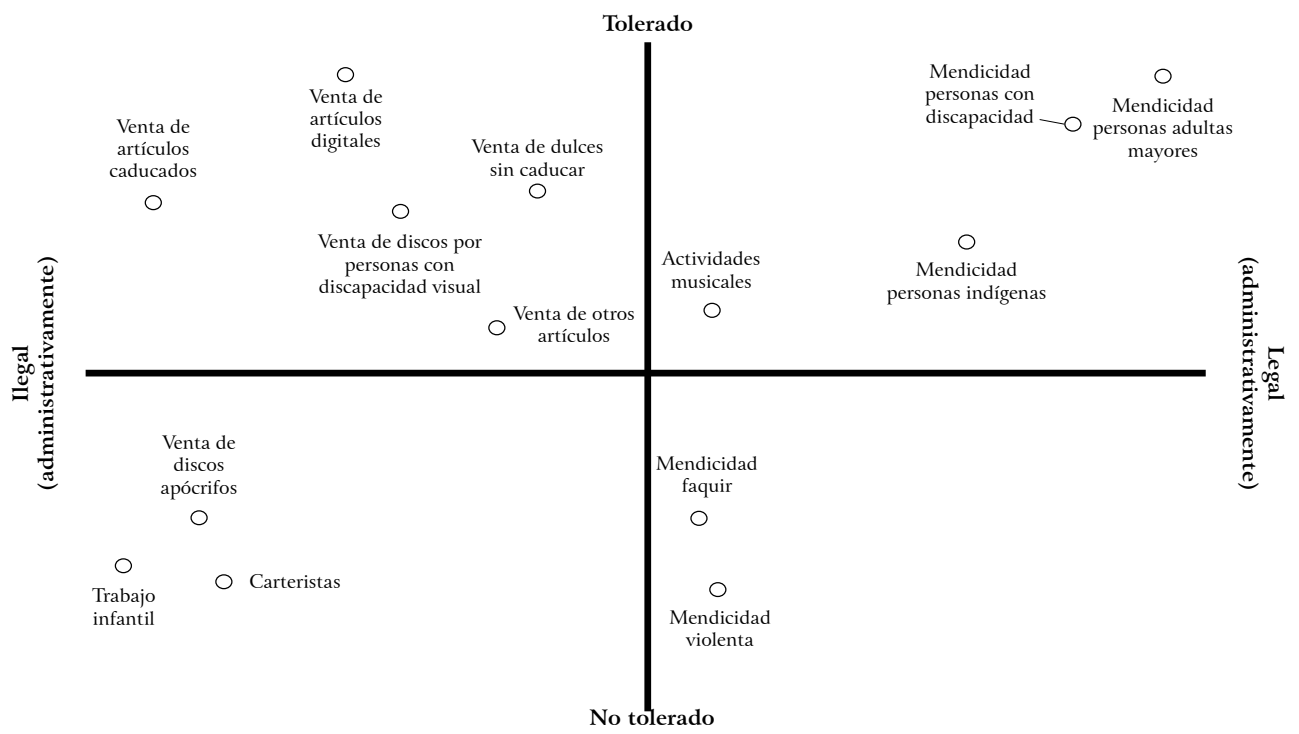

Figura 1 - Espacio socio-laboral y moral en el metro de la Ciudad de México.

Fuente: Elaboración propia.

el peso político que tienen las personas con discapacidad dentro de la opinión pública y política en la Ciudad de México (Serna Luna 2013), las autoridades han establecido un acuerdo de tolerancia por medio de una política de ordenamiento que les permite a las personas con discapacidad visual (PDV) vender sus productos, ofrecer sus servicios y pedir caridad, sin que sean perseguidas por los cuerpos policiacos que vigilan las instalaciones del STC Metro (Serna Luna 2013).

La tolerancia de la que gozan las poblaciones con discapacidad visual, y las personas mendicantes de origen rural (Serna Luna 2014), no es algo extensiva para el resto de las poblaciones de comerciantes, pedigüeños y artistas que realizan sus actividades económicas en el metro, pues, como mostraré en la siguiente sección, a lo largo de los años se ha instrumentado una serie de políticas y mecanismos que han buscado "erradicar al comercio informal" de la instalaciones del metro de la Ciudad de México.

Aunque en el esquema busqué identificar todas las actividades que constituyen el mercado popular en el metro, existen otras economías ilegales que se realizan por medio de los intercambios económicos de las autoridades encargadas de la vigilancia y seguridad en las instalaciones del STC Metro y los comerciantes populares. Me refiero a la corrupción, lo que se conoce en el argot popular como "mordidas", como el "cochupo", que le dan los comerciantes a los policías para que los dejen vender; a los pagos de las multas sin recibo que se les da a los jueces cívicos cuando los policías remiten a los comerciantes a los 
juzgados cívicos. Actividades que conforman aquello que podría comprenderse en lo que se entiende como las ilegalidades del Estado, y que constituyen la arquitectura de los mercados económicos de la ilegalidad (Beckert y Dewey 2017) en torno al comercio popular bajo la Ciudad de México. Estas ilegalidades se fundan en la negociación de las leyes y las sanciones que pesan sobre los comerciantes populares, las cuales presentaré a continuación.

\section{DE ERRADICACIONES Y REGULACIONES:}

\section{LAS POLÍTICAS EN CONTRA DEL COMERCIO POPULAR}

Desde los primeros años de funcionamiento del STC Metro, se especificó que el ejercicio del comercio en sus instalaciones era una actividad prohibida. Así lo señalan los artículos $19 .^{\circ}, 20 .^{\circ}$ y $21 .^{\circ}$ de las Normas Reglamentarias del STC Metro de 1977. A la par del desarrollo del comercio popular, también se sofisticaron los reglamentos e instrumentaron una serie de políticas que buscaron erradicar el comercio popular, tanto en el espacio público como debajo de éste. El punto cumbre de esta política sería el año de 1992, en el que se instrumentarían una serie de leyes y políticas que buscaban erradicar el comercio popular en el Centro Histórico de la Ciudad de México, y que, curiosamente,

Figura 2

Intentos de regulación del comercio popular en el STC Metro.

\begin{tabular}{|c|c|c|}
\hline Año & Programa & Acciones \\
\hline 1997 & $\begin{array}{l}\text { Reubicación de comerciantes en el } \\
\text { pasaje Zócalo-Pino Suárez }\end{array}$ & $\begin{array}{l}\text { Construcción de la plaza Pino Suárez y de las plazas } \\
\text { San Antonio Abad l y } 2 \text { (hoy extintas) }\end{array}$ \\
\hline 2008 & $\begin{array}{l}\text { Programa para Erradicar el Comercio } \\
\text { Ambulante en las Instalaciones y } \\
\text { Material Rodante del STC }\end{array}$ & $\begin{array}{l}\text { La Secretaría del Trabajo gestionó } 9 \text { millones de pesos } \\
\text { para cursos de capacitación y becas para crear socieda- } \\
\text { des cooperativas para las } 2856 \text { personas registradas en } \\
\text { el censo que levanto el STC }\end{array}$ \\
\hline 2010 & $\begin{array}{l}\text { Programa de Regularización del } \\
\text { Comercio Ambulante en las } \\
\text { Instalaciones y Material Rodante } \\
\text { del STC }\end{array}$ & $\begin{array}{l}\text { Las autoridades construyeron } 120 \text { espacios comer- } \\
\text { ciales, } 9 \text { salas de masaje y la instalación de espacios } \\
\text { musicales para personas con discapacidad visual. Se } \\
\text { crearon } 310 \text { locales comerciales con una inversión de } \\
\text { casi } 11.500 .000 \text { pesos. La renta por cada local era de } \\
\text { entre } 800 \text { y } 1000 \text { pesos. Se crearon } 5 \text { cooperarivas }\end{array}$ \\
\hline 2014 & $\begin{array}{l}\text { Programa para la Integración a la } \\
\text { Economía Formal de los } \\
\text { Comerciantes al Interior del STC }\end{array}$ & $\begin{array}{l}\text { Se destinaron } 30.280 .500 \text { pesos y } 9.000 .000 \text { de pesos } \\
\text { más, para capacitar a } 2500 \text { comerciantes inscritos en } \\
19 \text { organizaciones de comerciantes del Metro. }\end{array}$ \\
\hline
\end{tabular}


comenzarían con el retiro de comerciantes de las instalaciones del metro que se encuentran en el perímetro de la zona histórica y cultural de la Ciudad de México (Cross 1998). No me extenderé en demasía en la coyuntura política que siguió la saga del "combate al comercio popular" (Zaremberg 2011). Lo que me interesa es destacar que, a partir de este momento, se construiría el referente contemporáneo del combate al comercio popular en la Ciudad de México.

Por distintas razones, cada uno de estos proyectos ha fracasado en su intento por regular u ordenar el comercio popular. Gran parte de estos errores descansan en el hecho de que no se ha realizado un diagnóstico adecuado sobre el fenómeno, partiendo del desconocimiento de su magnitud demográfica. En cambio, ante la carencia de soluciones integrales que respondan al fenómeno socioeconómico que representa el "comercio informal", las autoridades de las distintas administraciones del STC Metro se han encargado de fortalecer los instrumentos jurídicos para sancionar y castigar esta actividad económica, la cual es una clara muestra de las desigualdades que padecen los habitantes de la Ciudad de México.

En la actualidad, el Reglamento de la Ley de Movilidad del Distrito Federal, expedido en 2017 (Gobierno de la Ciudad de México, 2017), es el instrumento jurídico que, en sus artículos $223 .^{\circ}, 230 .^{\circ}$, fracción III, y artículo $230 .^{\circ}$, fracciones XIV y XX, prohíbe el comercio en el transporte público. ${ }^{7}$ No obstante, no existe una normatividad jurídica que sancione de manera clara las prohibiciones que marca el Reglamento de la Ley de Movilidad del Distrito Federal. En cambio, las infracciones señaladas en este marco jurídico son sancionadas con base en la Ley de Cultura Cívica (Gobierno del Distrito Federal 2004).

Esta línea jurídica se ha expresado en la política de "cero tolerancia", la cual consiste en el incremento de la presencia de policías en el metro y el recrudecimiento de la aplicación de las sanciones administrativas en contra de los comerciantes populares. La idea de "cero tolerancia" se inspiró en las políticas que el ex alcalde de Nueva York, Rudolph Giuliani, había implementado para combatir el crimen durante su administración. ${ }^{8}$ Durante la jefatura de

7 Artículo 223. ${ }^{\circ}$ : III - Invadir cualquier área que no esté destinada al transporte de los usuarios, y en particular, las vías, carriles confinados, o los túneles por donde circulen los vehículos de este tipo de transporte. Artículo $230 .^{\circ}$ : XIV - Ejercer el comercio ambulante, en las unidades, carros y/o vagones, andenes, estaciones, túneles, corredores, escaleras, zonas de acceso, salidas y zonas de distribución y zonas de acceso y salida de las estaciones en un polígono de 25 metros. XX - Obstaculizar zonas de acceso, salidas, unidades, carros y/o vagones, andenes, estaciones, túneles, corredores, escaleras y en general, todos aquellos puntos de circulación peatonal y del propio medio de transporte.

8 “... el Grupo Giuliani señala que sus recomendaciones están orientadas por los elementos clave para el éxito que tuvieron en Nueva York y que fueron, principalmente, el sistema de información Compstat (que en realidad es un modelo de administración, localización de recursos y evaluación permanente de la acción policial) y el enfoque de la teoría de ventanas rotas de George Kelling como modelo de actuación policial. La mayoría de las recomendaciones tiene esa orientación y están [continua] 
gobierno de Marcelo Ebrard se contrató la asesoría del Grupo Giuliani, ${ }^{9}$ el cual emitiría 146 recomendaciones, que serían publicadas el 7 de agosto del 2003 por la Secretaría de Seguridad Pública.

En resumen, el concepto de seguridad en el espacio público desde la perspectiva de la "cero tolerancia" se podría condensar en la siguiente recomendación hecha por el grupo Giuliani:

"Respecto de la vialidad y las denominadas 'faltas menores o administrativas', cuestiones decisivas para la calidad de vida de los habitantes, la estrategia seguida en la ciudad durante la última década ha sido exactamente opuesta a la doctrina de las 'ventanas rotas'. Las leyes y disposiciones reglamentarias han sido cada vez más permisivas y complicadas de aplicar. Todo ello derivado tal vez por la idea de que la policía no es digna de confianza y no va a ser reformada en el futuro inmediato para serlo. En consecuencia, lo único que se puede hacer es limitar las faltas sancionables y restringir las facultades que puedan propiciar corrupción." (SSP 2003: 36)

El endurecimiento de los marcos jurídicos y del actuar policiaco resultó en un paulatino incremento de la presencia de efectivos de seguridad en las instalaciones del metro, y en un protagonismo de los jueces cívicos (Azuela 2014) como actores claves dentro de la impartición de justicia en la Ciudad de México, con lo cual los juzgados cívicos se convirtieron en escenarios importantes para la impartición de justicia en la ciudad. No obstante, existe una cara oscura dentro de todo este movimiento de hipersecuritización del espacio público (Davis 2013), la cual se expresa en la construcción de la infracción cívica como una conducta cercana al delito. En este sentido, vale la pena destacar la distinción jurídica que existe entre ambos conceptos.

El delito es una conducta grave que perturba el orden público y que viola los códigos penales que son emitidos por los poderes estatales y federales, por ejemplo, el robo o el asesinato. Así, en el artículo 7. ${ }^{\circ}$ del Código Penal Federal de los Estados Unidos Mexicanos,

"Artículo 7. - Delito es el acto u omisión que sancionan las leyes penales. En los delitos de resultado material también será atribuible el resultado típico producido al que omita impedirlo, si éste tenía el deber jurídico de evitarlo. En estos casos se considerará que el resultado es consecuencia de una conducta omisiva, cuando se determine que el que omite impedirlo 
tenía el deber de actuar para ello, derivado de una ley, de un contrato o de su propio actuar precedente." 10

En cambio, la falta administrativa es una conducta que, desde un punto de vista moral, afecta al orden público. Las sanciones por cometer este tipo de conductas pueden ser amonestaciones por parte de las autoridades, multas para resarcir el daño material o moral que las conductas pudieran haber ocasionado, y privaciones administrativas de la libertad, que no pueden ser mayores a las 36 horas de arresto. Por último, las faltas administrativas son sancionadas por la Ley de Cultura Cívica. Por medio de la cual, aunque no existe mucha claridad al respecto, ya he hablado sobre cómo se conceptualiza el comercio popular en la vía y el transporte público, como una conducta que impide la libre movilidad de las personas, como un uso indebido de los espacios públicos y como una forma de ocupar espacios de acceso restringido.

El combate al comercio popular en el metro de Ciudad de México abarca a todas las poblaciones. Una política que desde finales del 2013 cobró tintes más álgidos, pues las autoridades del STC Metro prometieron que, como uno de los beneficios del incremento de dos pesos en el costo del boleto del metro, se retiraría a todo el "comercio informal" de las estaciones del STC Metro (2014). Una medida que se reforzaría con la llegada de Jorge Gaviño al frente del STC Metro en el verano del 2016. Una de las primeras acciones de Gaviño fue anunciar el incremento de la presencia de elementos de la PBI, cuerpo policiaco privado que se contrató para vigilar las estaciones del metro, con la consigna de remitir ante el juzgado cívico a toda persona que ejerciera el comercio popular en el STC Metro.

Esta medida, según los comerciantes, desató una ola de vejaciones a sus derechos humanos por parte de los efectivos de la PBI y por otros efectivos que encabezan los operativos para "erradicar el comercio informal en el metro", como el "grupo lagartos", "grupo topos", "grupo murciélagos" pertenecientes a la Secretaría de Seguridad. Así mismo, las personas que comercian en el metro denunciaron abusos al interior de los juzgados cívicos destinados a la atención de las infracciones administrativas realizadas en el STC Metro, especialmente en los juzgados 33 y el Juzgado de Guerrero.

Por otro lado, el aumento de la presencia policiaca favoreció la construcción de una red de aplicación discrecional de las leyes que se sumó a los clásicos "moches" con los que los líderes de comerciantes negociaban con las autoridades de seguridad la tolerancia de vender en el metro. Esta forma de aplicar las sanciones incluye a los jueces cívicos que se encargan de aplicar las sanciones y multas en los juzgados cívicos por concepto del comercio popular en el metro.

10 De ello, se derivan otra serie de atenuantes que incluyen la duración del delito, su carácter culposo o doloso, entre otros. 
Esta estructura de la aplicación discrecional de la ley se sumó a las economías ilegales que explotan el metro de la Ciudad de México.

\section{"SOMOS LA CAJA CHICA DEL GOBIERNO": LAS FUNCIONES SOCIALES, ECONÓMICAS Y POLÍTICAS DEL COMERCIO POPULAR}

El Tejoncito es un vendedor de más de 50 años, 43 de los cuales ha vendido en los vagones del metro. Él me enseñó el oficio de ser vagonero, un saber que incluye el conocimiento de varias expresiones sobre la relación que han tenido los vagoneros con las autoridades y el gobierno de la Ciudad de México. Una de estas expresiones refiere a qué ellos sienten que son "la caja chica del gobierno", una expresión que se refiere a que, especialmente en tiempos electorales o cuando está por salir una administración del gobierno, se refuerzan los operativos policiacos en el metro y con ello aumenta el número de remisiones que realizan los policías y, por ende, la presentación y pago de multas en el juzgado cívico.

Figura 3

Remisiones en juzgado cívico por alcaldía 2016-2018

\begin{tabular}{|c|c|c|c|c|c|c|c|c|}
\hline Alcaldía & 2016 & $\%$ & 2017 & $\%$ & 2018 & $\%$ & Total & $\%$ \\
\hline Cuauhtémoc & 5.478 & 61,5 & 17.156 & 58,03 & 17.601 & 45,64 & 40.235 & 165,17 \\
\hline Venustiano Carranza & 961 & 10,8 & 2.316 & 7,83 & 5.518 & 14,3 & 8.795 & 11,42 \\
\hline Iztapalapa & 711 & 8 & 1.956 & 6,62 & 1.834 & 4,76 & 4.501 & 5,84 \\
\hline Benito Juárez & 446 & 5 & 1.738 & 5,9 & 2.511 & 6,51 & 4.695 & 2,1 \\
\hline Iztacalco & 411 & 4,6 & 1.787 & 6,04 & 2.169 & 5,62 & 4.367 & 5,67 \\
\hline Miguel Hidalgo & 405 & 4,6 & 1.221 & 4,13 & 4.038 & 10,47 & 5.664 & 7,35 \\
\hline Gustavo A. Madero & 303 & 3,4 & 1.682 & 5,69 & 2.812 & 7,29 & 4.797 & 6,23 \\
\hline Coyoacán & 129 & 1,5 & 1.255 & 4,25 & 1.257 & 3,26 & 2.641 & 3,43 \\
\hline Azcapotzalco & 31 & 0,35 & 12 & 0,04 & 609 & 1,58 & 652 & 0,85 \\
\hline Álvaro Obregón & 21 & 0,24 & 221 & 0,75 & 212 & 0,55 & 454 & 0,59 \\
\hline Cuajimalpa & 1 & 0,01 & 1 & 0,003 & 0 & 0 & 2 & 0 \\
\hline Tlahuác & 1 & 0,01 & 0 & 0 & 0 & 0 & 1 & 0 \\
\hline Magdalena Contreras & 0 & 0 & 217 & 0,73 & 0 & 0 & 217 & 0,28 \\
\hline Milpa Alta & 0 & 0 & 0 & 0 & 0 & 0 & 0 & 0 \\
\hline Tlalpan & 0 & 0 & 0 & 0 & 0 & 0 & 0 & 0 \\
\hline Xochimilco & 0 & 0 & 0 & 0 & 0 & 0 & 0 & 0 \\
\hline Total & 8.898 & 100 & 29.562 & 100 & 38.561 & 100 & 77.021 & 100 \\
\hline
\end{tabular}

Fuente: Elaborada con base en la información proporcionada al 9/12/18 por la Subsecretaría de Información e Inteligencia Policial de la PGJDMX. 
Como lo muestran las cifras recopiladas sobre el número de remisiones realizadas desde el 2016, se han incrementado notoriamente el número de remisiones en los juzgados cívicos de la Ciudad de México por causa de la infracción de "venta informal en las instalaciones del STC Metro".

La tabla muestra una evidente concentración de las remisiones en los juzgados cívicos localizados en la alcaldía Cuauhtémoc; sobre ello me explayaré más adelante, pues es un elemento importante que me permitirá mostrar la explotación económica de las remisiones de comerciantes populares por parte de las autoridades. En contraste, algunas alcaldías presentan ínfimos o nulos registros de remisiones. La concentración que tienen los juzgados cívicos de la alcaldía de Cuauhtémoc en relación con el número de remisiones de comerciantes populares del STC Metro se puede explicar a partir de factores espaciales, económicos, sociales y políticos. Comenzaré por la cuestión espacial. Respecto de las alcaldías en las que se encuentra al menos una estación del STC Metro, la de Cuauhtémoc es la que concentra el mayor número de estaciones dentro de su demarcación, con 46 estaciones correspondientes a seis líneas distintas del STC Metro.

Aunado a ello, se debe destacar que gran parte de esas 46 estaciones atraviesan y circundan el centro histórico de la Ciudad de México, una de las zonas que contiene el mayor número de comercios, museos, zonas históricas de la ciudad y que, por ende, genera las mayores concentraciones y afluencias de personas. Condiciones de economía urbana (Topalov 1979) que derivan en una mayor generación de plusvalores urbanos (Garza 2011). Los cuales, históricamente, también han sido explotados por las economías populares (Azuela 1990; Lezama de la Torre 1991; Crossa 2009; Alba, Lins Ribeiro y Mathews 2015). Por ello, la referencia a las afluencias registradas en las estaciones es importante, pues es un indicador que permite ubicar, tanto para las actividades económicas impulsadas por el gobierno como por las actividades del mercado popular, aquellas estaciones que ofrecen mayores ganancias económicas.

En concordancia, es en este poligono en donde se concentran los juzgados cívicos a los que son remitidas las personas que son detenidas por "comercio informal en el metro". Según las mismas cifras de remisiones de los juzgados cívicos, en el período que presentó, es en tres de estos juzgados en los que se concentra el mayor número de remisiones: el Juzgado $\mathrm{CUH}-2$, localziado cerca del metro Revolución; el Juzgado CUH-4. Al que se debería de sumar el juzgado cívico ubicado en las instalaciones de la estación del metro Guerrero. 


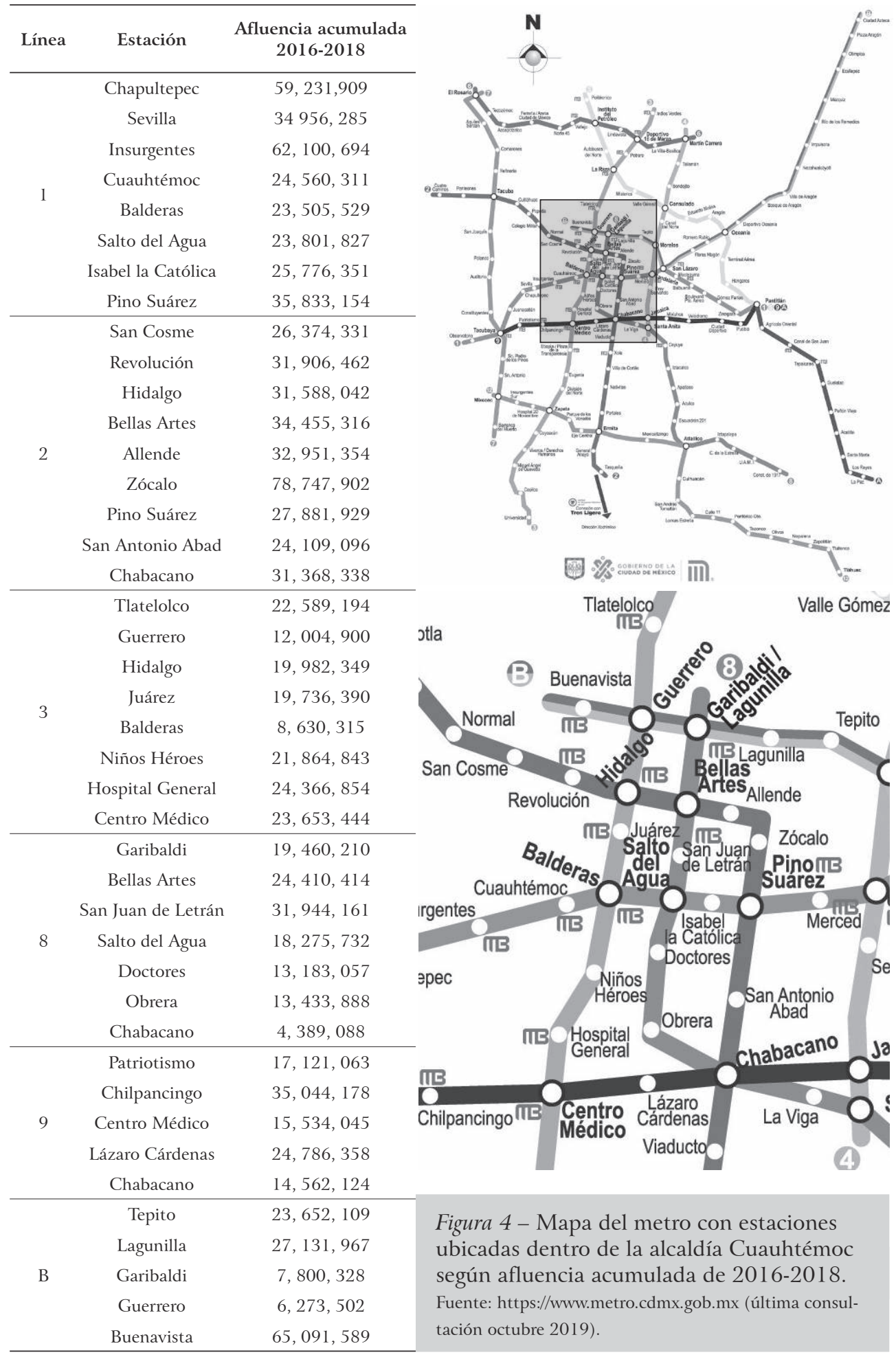




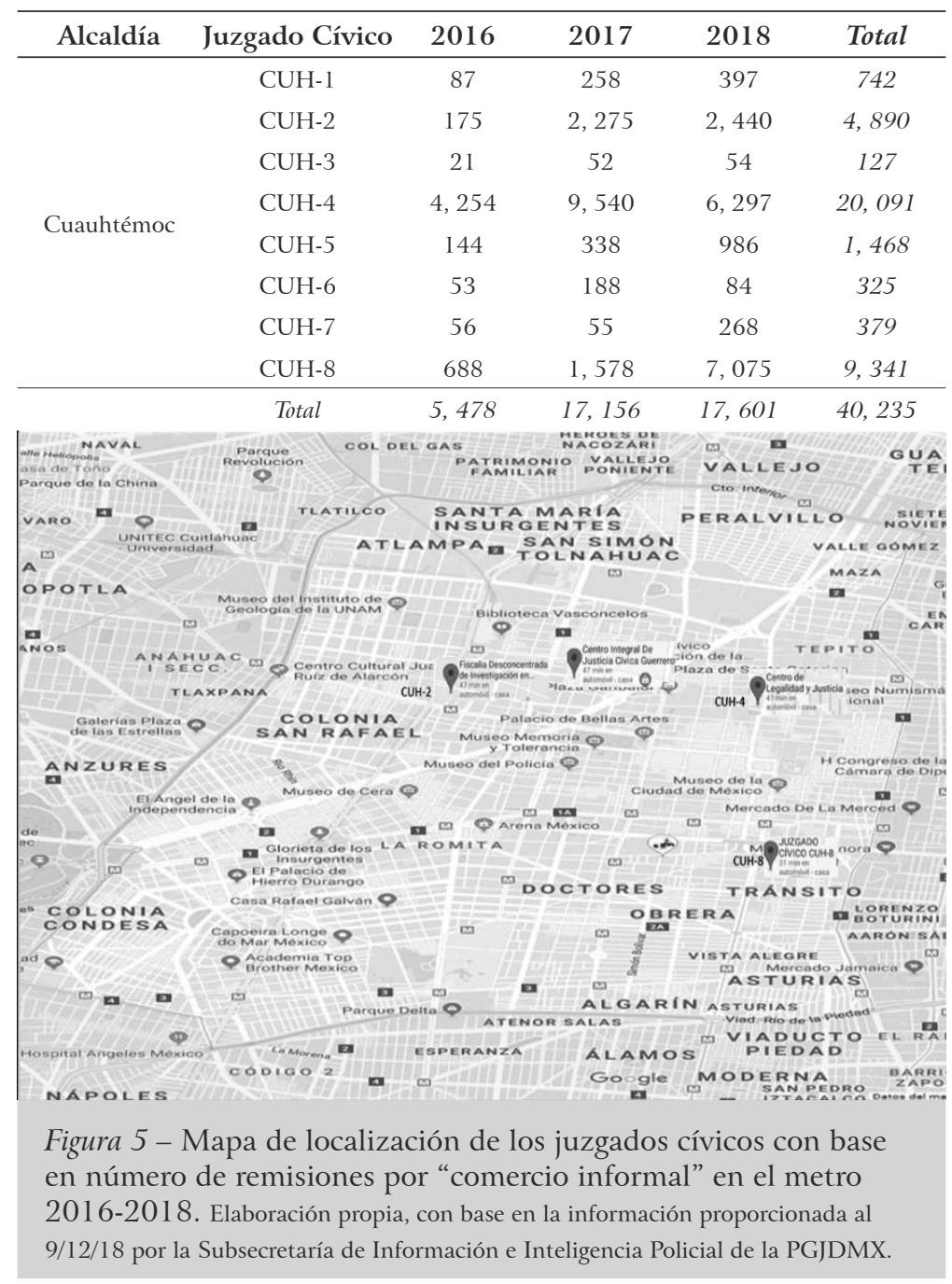

\section{CONSIDERACIONES FINALES}

$\mathrm{Al}$ atenderse el fenómeno del comercio popular en el metro desde una perspectiva que refuerza el brazo policiaco del Estado, las relaciones entre comerciantes, jueces y policías se han vuelto más tensas. Al punto de que se ha generado un clima de violencia entre ambos grupos que, incluso, han trastocado las relaciones de negociación de la ley que, en gran medida, servía para normar las relaciones entre policías y comerciantes. El endurecimiento de la política de cero tolerancia en contra del comercio popular en el metro, que ha emprendido la administración actual, ha derivado en protestas por parte de los comerciantes, debido a los abusos policiacos que han sufrido a manos de los cuerpos de 
seguridad. El 20 de marzo del 2020, en las postrimerías de la contingencia sanitaria por Covid-19 en la Ciudad de México, la violencia policiaca alcanzaría su máxima expresión, cuando un grupo de policías, al intentar remitir a Luis Orozco, un vendedor de congeladas de la línea B, lo golpearon y ocasionaron su muerte (Serna Luna 2020b). Este hecho tensó más las relaciones entre autoridades y comerciantes, como entona el rap de Dupa:

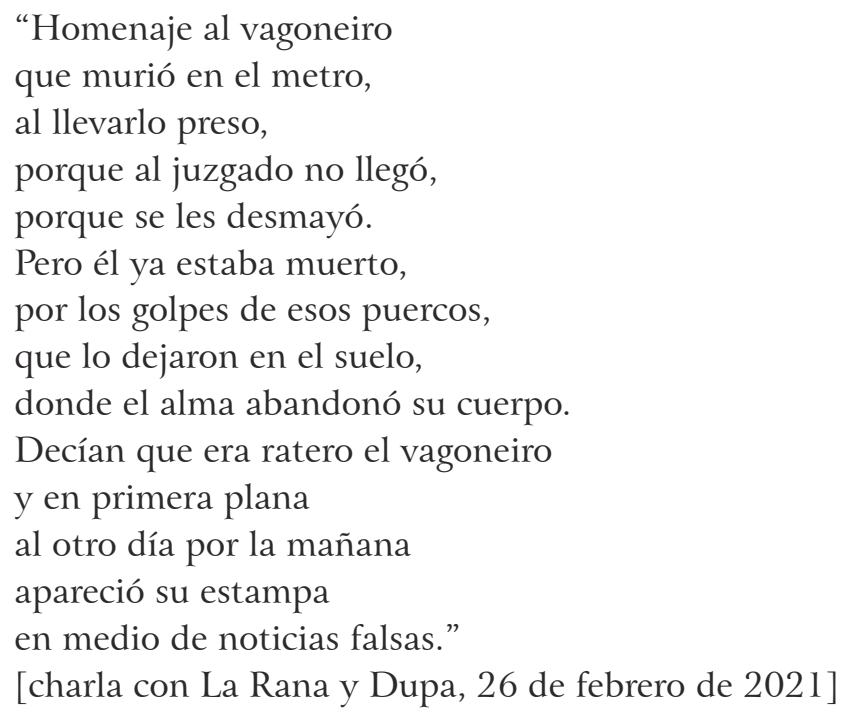

Para evitar que la violencia incremente y se derive en más decesos, es necesario que se construya una política que atienda el fenómeno del comercio popular en el metro, lejos de los estigmas morales que han pesado sobre este grupo poblacional. Pues estos estigmas que son la base de los marcos jurídicos con los que se gobierna el espacio público de la ciudad impiden que se avance en el reconocimiento de los derechos humanos de estas poblaciones y en el acceso al derecho humano al trabajo que garantiza la propia Constitución Política de la Ciudad de México. Un tema de inclusión y justicia social que no es menor, tendiendo en cuenta que gran parte de la población económicamente activa que habita en la Ciudad de México se emplea y produce riqueza gracias a alguna de las muchas actividades que conforman el mercado popular en y debajo de la Ciudad de México. 


\section{BIBLIOGRAFÍA}

ALBA, Carlos, Gustavo LINS RIBEIRO, y Gordon MATHEWS, 2015, La Globalización desde Abajo: La Otra Economía Mundial. México, DF: Fondo de Cultura Económica/El Colegio de México.

AZUELA, Antonio, 1990, "Fuera del huacal, aun en la calle: el comercio y el espacio público en el centro de la ciudad", Trace, 17: 20-24.

AZUELA, Antonio, 2014, "Introducción”, in Antonio Azuela y Miguel Ángel Cancino (eds.), Jueces y Conflictos Urbanos en América Latina. México, DF: PAOT, 7-30.

BECKERT, Jens, y Matías DEWEY, 2017, The Architecture of Illegal Markets: Towards an Economic Sociology of Illegality in the Economy. Oxford: Oxford University Press.

BOURDIEU, Pierre, 1988, La Distinción: Criterios y Bases Sociales del Gusto. Madrid: Taurus.

CASTELLS, Manuel, y Alejandro PORTES, 1995, "El mundo debajo: orígenes, dinámica y efectos de la economía informal”, in Víctor Tokman (ed.), El Sector Informal en América Latina: Dos Décadas de Análisis. México, DF: Editorial Conaculta, 233-270.

CROSS, John, 1998, Informal Politics: Street Vendors and the State in Mexico City. Stanford, CA: Standford University Press.

CROSSA, Verónica, 2009, "Resisting the entrepreneurial city: street vendor's struggle in México City's historic center", International Journal of Urban and Regional Research, 33: 43-63.

CROSSA, Verónica, 2018, Luchando por Un Espacio en la Ciudad de México: Comerciantes Ambulantes y el Espacio Público Urbano. México, DF: El Colegio de México.

CRUZ, Mario Barbosa, 2008, El Trabajo en las Calles: Subsistencia y Negociación Política en la Ciudad de México a Comienzos del Siglo XX. México, DF: El Colegio de México/Centro de Estudios Históricos / Universidad Autónoma Metropolitana, Unidad Cuajimalpa.

DAVIS, Diane, 2013, "Zero-tolerance policing, stealth real estate development, and the transformation of public space evidence from Mexico City", Latin American Perspectives, 40 (2): 53-76.

DENNING, Michael, 2010, “Wageless life”, New Left Review, 66: 79-97.

GARZA, Gustavo, 2011, Teoría de las Condiciones y los Servicios Generales de la Producción. México, DF: El Colegio de México.

GOBIERNO DE LA CIUDAD DE MÉXICO, 2017, Reglamento de la Ley de Movilidad del Distrito Federal. Ciudad de México: Gaceta Oficial de la Ciudad de México.

GOBIERNO DEL Distrito FEDERAL, 2004, Ley de Cultura Cívica. México, DF: Gaceta Oficial del Distrito Federal.

HART, Keith, 1973, "Informal income opportunities and urban employment in Ghana", The Journal of Modern African Studies, 11 (1): 61-89.

HOBSBAWN, Eric, 2001, Rebeldes Primitivos: Estudio sobre las Formas Arcaicas de los Movimientos Sociales en los Siglos XIX y XX. Barcelona: Crítica.

LEZAMA DE LA TORRE, José Luis, 1991, "Ciudad conflicto: el comercio ambulante en el DF”, Estudios Demográficos y Urbanos, Vol. 6, n. ${ }^{\circ} 3$ (18): 649-675.

LIDA, Clara E., 1997, “¿Qué son las clases populares? Los modelos europeos frente al caso español en el siglo XIX”, Historia Social, 1997: 3-21.

MARX, Karl, 1962, "Manuscritos económicos-filosóficos”, in Erich Fromm, Marx y su Concepto de Hombre. México, DF: FCE.

MARX, Karl, 1999, El Capital: Contribución a la Crítica de la Economía Política. México, DF: FCE. 
MARX, Karl, 2003, El 18 Brumario de Luis Bonaparte, Madrid, Fundación Federico Engels. PACHECO, María Edith, 2004, Ciudad de México, Heterogénea y Desigual: Un Estudio sobre el Mercado de Trabajo. México, DF: El Colegio de México.

PIRES, Lenin, 201 1, Esculhamba, mas não Esculacha! Uma Etnografia dos Usos Urbanos dos Trens da Central do Brasil. Río de Janeiro: Editora da Universidade Federal Fluminense.

SCHOUTEN, Peer, 2013, "Theory talk 56: Keith Hart on the informal economy, the great transformation, and the humanity of corporations", Theory Talks. Disponible en $<$ http:// www.theorytalks.org/2013/06/theory-talk-56.html > (última consultación en enero 2022).

SERNA LUNA, Erick, 2013, Los que Laboran en la Oscuridad: La Informalidad Regulada de las Personas con Discapacidad Visual que Trabajan en el STC Metro. México, DF: El Colegio de México, tesis de máster en Estudios Urbanos.

SERNA LUNA, Erick, 2014, "De la sierra al subterráneo: los supuestos migrantes rurales de la sierra norte de Puebla y la economía de la mendicidad en el metro de la Ciudad de México", in María Isabel Angoa Pérez, Alejandro Sánchez Zárate y Isaías Aguilar Huerta (eds.), Memorias $1 .{ }^{\circ}$ Congreso Internacional "Economía, Medio Ambiente y Territorio": Caleidoscopio de la Ciudad Contemporánea. Puebla, México: Benemérita Universidad de Puebla, 176-200.

SERNA LUNA, Erick, 2020a, Gobernar Bajo la Ciudad: Etnografía sobre la Gobernanza del Comercio Popular en el Metro de la Ciudad de México. Ciudad de México: El Colegio de México, tesis de doctorado en Estudios Urbanos y Ambientales.

SERNA LUNA, Erick, 2020b, "Contingencia en el subterráneo: el COVID-19 en relación con el comercio popular en el metro de la Ciudad de México”, in Gian Carlo Delgado Ramos y David López García (eds.), Las Ciudades ante el COVID-19: Nuevas Direcciones para la Investigación Urbana y las Políticas Públicas. México, DF: Plataforma de Conocimiento para la Transformación Urbana, 174-183.

SSP - SECRETARÍA DE SEGURIDAD PÚBLICA, 2003, Reporte Giuliani - SSPk. México, DF: SSP.

STC METRO - SISTEMA DE TRANSPORTE COLECTIVO METRO, 2014, Once Compromisos Asumidos por el Sistema de Transporte Colectivo. México, DF: Fideicomiso Maestro del Metro. Disponible en < https://metro.cdmx.gob.mx/storage/app/media/Fideicomiso/info rmel lcompromisos.pdf > (última consultación en enero 2022).

TOPAlOV, Christian, 1979, La Urbanización Capitalista, Algunos Elementos para Su Análisis. México, DF: Edicol.

ZAREMBERG LIS, Gisela, 2011 , ¿Corporativismo Informal? Organizaciones de Ambulantes y Partidos Políticos a partir de la Alternancia Electoral en México, Distrito Federal (2000-2005). Buenos Aires: Clacso. 